\title{
Effect of temperature and carpel size during pre-anthesis on potential grain weight in wheat
}

\author{
D. F. CALDERINI*, L. G. ABELEDO, R. SAVIN AND G. A. SLAFER \\ Departamento de Producción Vegetal, Facultad de Agronomía, Universidad de Buenos Aires, Av. San Martín \\ 4453, 1417 Buenos Aires, Argentina
}

(Revised MS received 21 October 1998)

\begin{abstract}
SUMMAR Y
The effect of environmental conditions immediately before anthesis on potential grain weight was investigated in wheat at the experimental field of the Faculty of Agronomy (University of Buenos Aires, Argentina) during 1995 and 1996. Plants of two cultivars of wheat were grown in two environments (two contrasting sowing dates) to provide different background temperature conditions. In these environments, transparent boxes were installed covering the spikes in order to increase spike temperature for a short period (c. 6 days) immediately before anthesis, i.e. between ear emergence and anthesis. In both environments, transparent boxes increased mean temperatures by at least $3.8{ }^{\circ} \mathrm{C}$. These increases were almost entirely due to the changes in maximum temperatures because minimum temperatures were little affected. Final grain weight was significantly reduced by higher temperature during the ear emergence-anthesis period. It is possible that this reduction could be mediated by the effect of the heat treatment on carpel weight at anthesis because a curvilinear association between final grain weight and carpel weight at anthesis was found. This curvilinear association may also indicate a threshold carpel weight for maximizing grain weight.
\end{abstract}

\section{INTRODUCTION}

Grain yield in wheat has been commonly found to be associated with the number of grains per $\mathrm{m}^{2}$ (Fischer 1985; Magrin et al. 1993) and much research has been carried out to elucidate the causes of differences in number of grains per $\mathrm{m}^{2}$ in relation to both environmental conditions (Fischer 1985) and genetic improvement (Loss et al. 1989; Slafer et al. 1994). Although less variable than number of grains per $\mathrm{m}^{2}$, individual grain weight is also an important source of variation in grain yield. However, there is a rather poor understanding of the determinants of grain weight in wheat.

An early hypothesis was that changes in grain weight were associated with changes in the availability of assimilates for grain growth. Several authors (see Slafer \& Savin 1994), have manipulated source: sink ratios at (or after) anthesis to test this hypothesis. Although some of them (Fischer \& HilleRisLambers 1978; Simmons et al. 1982) concluded that final grain weight was somewhat limited by the source, a wider

* To whom all correspondence should be addressed at: Facultad de Agronomía, Cátedra de Cereales, Av. San Martin 4453 (1417) Buenos Aires, Argentina. E-mail: dfcalder@mail.retina.ar analysis (Slafer \& Savin 1994) showed that grain growth of modern cultivars is unlikely to be source limited. Similar results have been published for cultivars released at different eras (Kruk et al. 1997) and for Rht isogenic lines (Miralles \& Slafer 1995). Therefore, most differences in grain weight must be related to those in grain weight potential (i.e. the intrinsic capacity of grains to accumulate dry matter as defined by Bremner \& Rawson 1978).

Temperature during grain-filling has been identified as a major environmental factor affecting grain weight and its physiological determinants (Sofield et al. 1977). This effect has also been found when relatively short periods of high temperature occur during grainfilling in wheat (Stone \& Nicolas 1995) and barley (Savin \& Nicolas 1996). These reports (mostly based on controlled-environment studies) have clearly demonstrated that high temperatures during the grainfilling period reduce grain weight due to a reduction in the grain-filling duration (measured in calendar time), and this effect may not be reversed by increasing the availability of assimilates per grain (Slafer \& Miralles 1992). The importance of the period immediately before anthesis for the determination of potential grain weight has been largely disregarded. However, it is during this period that the structures of the ovary (grain pericarp after fertilization) are 
formed, and the importance of the pericarp tissues on early grain development was suggested many years ago (Rijven \& Banbury 1960). The observation that temperatures from the four-leaf stage to anthesis may modify final grain weight in wheat (Wardlaw 1994) suggests that there is a need to examine more closely pre-anthesis effects on potential grain weight. This is supported by the observation that in barley (Scott et al. 1983) there is a positive relationship between final grain weight and carpel weight at anthesis, suggesting that the carpel growth period may be critical for the determination of potential grain weight. In addition, the possibility that carpel weight is a determinant of differences in grain weight potential among grains from different positions of the spike has received little attention in research.

We aimed to determine whether spike temperatures during the period from ear emergence to anthesis contribute to the determination of potential grain weight in field-grown wheat plants, through effects on floret and carpel growth.

\section{MATERIALS AND METHODS}

The study was carried out during 1995 and 1996 at the experimental field of the Faculty of Agronomy, University of Buenos Aires ( $34^{\circ} 35^{\prime} \mathrm{S}, 58^{\circ} 29^{\prime} \mathrm{W}$, altitude $25 \mathrm{~m}$ ) on a silty clay loam soil (Aeric Argiudoll). Treatments consisted of the factorial combination of two sowing dates, 18 December $1995\left(\mathrm{~S}_{1}\right)$ and 27 March $1996\left(\mathrm{~S}_{2}\right)$, two high-yielding wheat cultivars (Pro INTA Federal and Buck Ombú), known to differ in their potential grain weight (Pedrol \& Castellarín 1989), and two temperature regimes for the growing spikes (control or heated spikes) during the period from ear emergence (at $50 \%$ of ear emergence) to anthesis, i.e. when carpels are growing rapidly. Although the sowings were not those commercially used they were chosen to expose the crops to extreme, though realistic, combinations of pre- and postanthesis conditions.

Experimental plots of 7 rows, $0 \cdot 20 \mathrm{~m}$ apart and $3 \mathrm{~m}$ long, oriented in a north-south direction were arranged in split-split-plot design with three replications. Main plots were assigned to sowing dates, subplots to cultivars and sub-subplots to the preanthesis thermal regimes. Sowing density was 400 and 350 plants $/ \mathrm{m}^{2}$ in $\mathrm{S}_{1}$ and $\mathrm{S}_{2}$, respectively. Mineral nitrogen was applied at sowing at $180 \mathrm{~kg} \mathrm{~N} /$ ha. Plots were irrigated from planting to maturity to supplement rainfall. Weeds were periodically removed by hand. Diseases and insects were prevented by spraying pesticides at the rates recommended by their manufacturers.

To increase the temperature during carpel growth, transparent acrylic boxes $(50 \mathrm{~cm}$ length, $20 \mathrm{~cm}$ height and $6.5 \mathrm{~cm}$ wide) with open bases were installed covering only the spikes (c. 15 contiguous plants in a central row) from their emergence to anthesis (i.e. during c. 6 days) in the heated treatment. Each box was supported at its southern end by a wooden stake. In $\mathrm{S}_{1}$, only one box per plot was installed but in $\mathrm{S}_{2}$ two boxes were installed in each plot with the objective of increasing the number of heated spikes. Daily maximum and minimum temperatures were recorded inside and outside the boxes with a digital thermometer (TFA, Germany).

During the crop cycle, the dates of booting, heading and anthesis were recorded using the scale proposed by Zadoks et al. (1974). Physiological maturity was assessed as the time when grain growth ceased. During the pre-anthesis period the dry weight of the carpels of each of the three most proximal florets (those closest to the rachis) in the four central spikelets of four main-shoot spikes per experimental unit were measured (only in controls) at mid-booting and c. 4 days after anthesis in $\mathrm{S}_{1}$ (see Table 1). In $\mathrm{S}_{2}$ carpel weight was measured at mid-booting, mid-heading and at $50 \%$ anthesis in controls. In $\mathrm{S}_{2}$, carpels of heated spikes were also measured at $50 \%$ anthesis (see Table 1). The carpels and grains corresponding to the three most proximal florets will be subsequently referred to as $\mathrm{C}_{1}, \mathrm{C}_{2}$ and $\mathrm{C}_{3}$ for measurements before anthesis and $\mathrm{G}_{1}, \mathrm{G}_{2}$ and $\mathrm{G}_{3}$ for measurements during the grain-filling period. Carpels or grains from positions 1 and 2 are collectively termed 'proximal carpels or grains' and $\mathrm{C}_{3}$ or $\mathrm{G}_{3}$ named 'distal carpel or grain'.

From anthesis onwards, one main-shoot spike from each replication was harvested at least twice weekly and the dry weight of $G_{1}, G_{2}$ and $G_{3}$ was recorded only for the control treatment in $\mathrm{S}_{1}$ and for both control and heated treatments in $\mathrm{S}_{2}$. Final grain weight for each grain category was estimated using a bi-linear model:

$$
\begin{array}{ll}
y=a_{1}+b_{1} x & \text { if }(x \leqslant c), \text { and } \\
y=a_{2}+b_{2} x & \text { if }(x>c)
\end{array}
$$

were $y$ is grain weight (mg), $a_{1}$ and $b_{1}$ the intercept $(\mathrm{mg})$ and the rate of grain-filling $(\mathrm{mg} /$ day), respectively, corresponding to the first stage (i.e. from anthesis to physiological maturity), $a_{2}$ and $b_{2}$ the intercept (mg) and the rate of grain-filling (mg/day), respectively, corresponding to the second stage (i.e. after physiological maturity), $x$ day after anthesis, and $c$ the total duration of the grain-filling period (days). Fitting was performed by an optimization technique (Jandell 1991). This model fits the data through an iterative procedure, producing reliable estimates of the grain filling duration and final grain weight (for more details see Miralles et al. 1996). For $\mathrm{S}_{1}$, the number of spikes subjected to the heated treatments (i.e. inside the boxes) were insufficient for the use of a bi-linear model. Therefore, in this treatment five spikes from each plot were used to 
Table 1. Timing of the measurements of carpel weight of three most proximal florets to the rachis from the four central spikelets of the cultivars Pro INTA Federal and Buck Ombú in 1995 and 1996

\begin{tabular}{|c|c|c|c|c|c|c|}
\hline \multirow[b]{2}{*}{ Treatment } & \multicolumn{3}{|c|}{$\mathrm{S}_{1}$} & \multicolumn{3}{|c|}{$\mathrm{S}_{2}$} \\
\hline & Booting & Heading & Anthesis & Booting & Heading & Anthesis \\
\hline Control & $50 \%$ & - & $50 \%+4 d$ & $50 \%$ & $50 \%$ & $50 \%$ \\
\hline Heated & n.a. & n.a. & - & n.a. & n.a. & $50 \%$ \\
\hline
\end{tabular}

-: no sample taken.

n.a.: not applicable as the heat treatment was imposed from heading to anthesis.

$50 \%$ : samples taken when $50 \%$ of the ears has reached anthesis.

$50 \%+4 \mathrm{~d}$ : samples taken 4 days after $50 \%$ of the ears has reached anthesis.

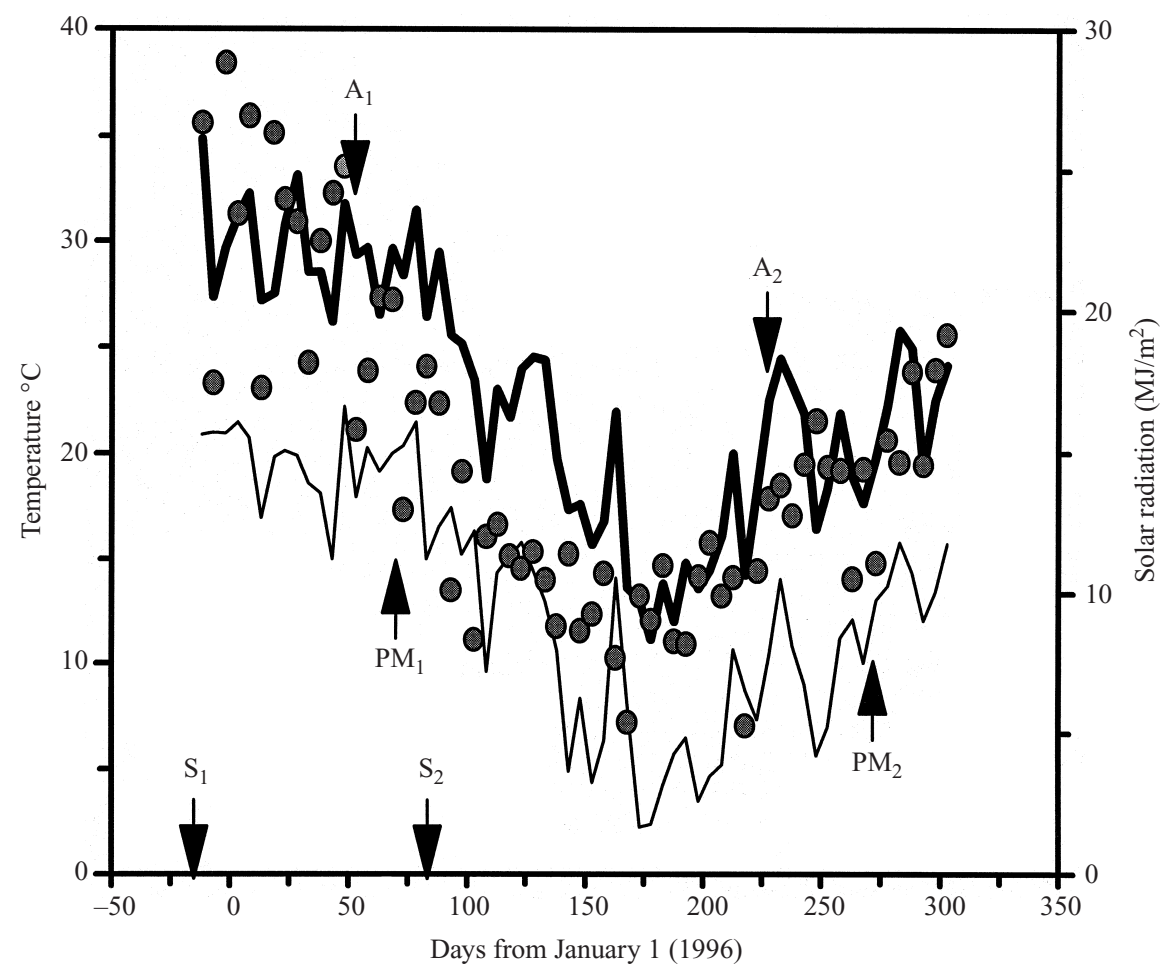

Fig. 1. Daily global solar radiation (-), maximum (-) and minimum temperature (-), averaged for 5-day periods from 1 January 1996. The arrows show the first $\left(S_{1}\right)$ and the second $\left(S_{2}\right)$ sowing dates, and the date of anthesis $(A)$ and physiological maturity (PM) corresponding to the first $\left(_{1}\right)$ and the second $\left(_{2}\right)$ sowings. Dates are the average of both cultivars.

determine final grain weight (averaged for each category of grain at harvest).

Data were subjected to analysis of variance. When comparisons were made between sowing dates, Error A (main plot) was used; for comparisons between cultivars or between thermal regimes, the magnitudes of Error B (subplot) and C (sub-subplot) were taken into account. In addition, linear and curvilinear regression analyses were performed.

\section{RESULTS}

The extreme sowing dates used in the present experiment strongly modified the environment in which the crop was grown (Fig. 1). Within each sowing date the cultivars showed similar anthesis date; however they differed by $c .8$ days at physiological maturity (Table 2). The period between booting and anthesis had a mean temperature of 
Table 2. Sowing, anthesis and physiological maturity dates for Pro INTA Federal and Buck Ombu' in the control treatments carried out in 1995 and 1996

\begin{tabular}{lccc}
\hline \hline Cultivar & Sowing & Anthesis & Maturity \\
\hline P Federal & $\mathrm{S}_{1} 12 / 18 / 95$ & $02 / 20 / 96$ & $03 / 24 / 96$ \\
& $\mathrm{~S}_{2} 03 / 27 / 96$ & $08 / 17 / 96$ & $09 / 25 / 96$ \\
B Ombú & $\mathrm{S}_{1} 12 / 18 / 95$ & $02 / 21 / 96$ & $03 / 16 / 96$ \\
& $\mathrm{~S}_{2} 03 / 27 / 96$ & $08 / 18 / 96$ & $10 / 03 / 96$ \\
\hline \hline
\end{tabular}

Table 3. Final grain weight of control treatments corresponding to the three floret positions closest to the rachis (i.e. $G_{1}, G_{2}$ and $G_{3}$ ) for cultivars $P$. Federal and $B$. Ombu in the first $\left(S_{1}\right)$ and second $\left(S_{2}\right)$ sowing date. Numbers between brackets show standard errors of the means

\begin{tabular}{lcccc}
\hline \hline Cultivar & $\begin{array}{c}\text { Sowing } \\
\text { date }\end{array}$ & $\begin{array}{c}\mathrm{G}_{1} \\
(\mathrm{mg})\end{array}$ & $\begin{array}{c}\mathrm{G}_{2} \\
(\mathrm{mg})\end{array}$ & $\begin{array}{c}\mathrm{G}_{3} \\
(\mathrm{mg})\end{array}$ \\
\hline P. Federal & $\mathrm{S}_{1}$ & $33 \cdot 9(2 \cdot 5)$ & $33 \cdot 2(2 \cdot 7)$ & $23 \cdot 0(2 \cdot 1)$ \\
& $\mathrm{S}_{2}$ & $35 \cdot 0(3 \cdot 4)$ & $34 \cdot 6(4 \cdot 6)$ & $25 \cdot 6(3 \cdot 7)$ \\
B. Ombú & $\mathrm{S}_{1}$ & $37 \cdot 2(2 \cdot 1)$ & $39 \cdot 7(3 \cdot 0)$ & $31 \cdot 6(2 \cdot 4)$ \\
& $\mathrm{S}_{2}$ & $44 \cdot 0(2 \cdot 1)$ & $44 \cdot 4(3 \cdot 4)$ & $38 \cdot 2(2 \cdot 4)$ \\
\hline \hline
\end{tabular}

c. $26^{\circ} \mathrm{C}$ in $\mathrm{S}_{1}$ for both cultivars; while in $\mathrm{S}_{2}$ it was c. $13.5^{\circ} \mathrm{C}$. During grain-filling, mean temperatures were $c .24^{\circ}$ and $15.5^{\circ} \mathrm{C}$ in $\mathrm{S}_{1}$ and $\mathrm{S}_{2}$, respectively. Solar radiation for the booting-anthesis period differed markedly between sowings, c. 23 and 9 $\mathrm{MJ} \mathrm{m}^{2} /$ day in $\mathrm{S}_{1}$ and $\mathrm{S}_{2}$, respectively. For the anthesis-physiological maturity period those values were 20 and $14 \mathrm{MJ} \mathrm{m}^{2} /$ day in $\mathrm{S}_{1}$ and $\mathrm{S}_{2}$, respectively (Fig. 1).

Grain weight was modified by both genotype $(P<0.001)$ and grain position $(P<0.001)$ in both sowings (Table 3 ). Considering grain position, a clear difference between proximal grains and $G_{3}$ was found both in $S_{1}$ and $S_{2}$ (Table 3 ). This pattern of differences is similar to that for final grain weight found for optimum sowing dates for these cultivars in Buenos Aires (38-42 mg for proximal grains and $28-35 \mathrm{mg}$ for $G_{3}$ ). Interactions between most factors on final grain weight were not significant, except that for cultivar $\times$ grain position $(P<0 \cdot 05)$.

Heat treatment consistently increased mean temperatures during the period between heading and anthesis, by 4.7 and $3.8^{\circ} \mathrm{C}$ in $\mathrm{S}_{1}$ and $\mathrm{S}_{2}$, respectively. These increases were entirely due to the increases in maximum temperatures (Fig. 2). Average maximum temperatures within the acrylic boxes and for the $c .6$ days before anthesis were 44.6 and $26 \cdot 8{ }^{\circ} \mathrm{C}$ in $\mathrm{S}_{1}$ and $\mathrm{S}_{2}$, respectively. Differences between heated treatment and the control in minimum temperature were

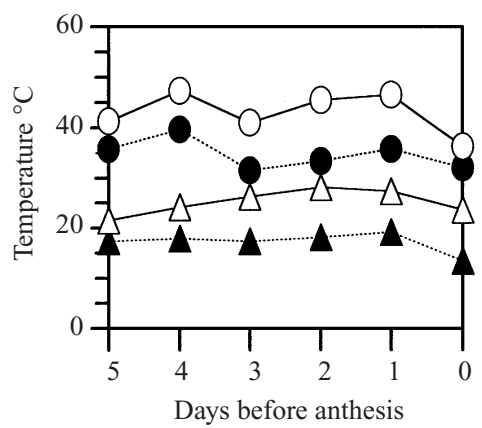

Fig. 2. Maximum temperatures during the period immediately prior to anthesis within the boxes (open symbols and continuous lines) and outside in the controls (closed symbols and dashed lines) in $\mathrm{S}_{1}$ (circles) and $\mathrm{S}_{2}$ (triangles).

negligible $\left(<0 \cdot 5^{\circ} \mathrm{C}\right)$. The heat treatment significantly decreased final grain weight $(P<0 \cdot 01)$, the decrease depending on sowing date (interaction significant at $P<0 \cdot 01)$. Cultivars showed different responses to the heat treatment. For example, P. Federal was more affected (19.5\% decrease in $\mathrm{S}_{2}$, averaging across all grain positions) than $\mathrm{B}$. Ombú $(6 \cdot 3 \%$ decrease $)$ in that sowing. In addition, final grain weights from proximal and distal positions were differently affected by the heat treatment. The weights of proximal grains were less reduced than $\mathrm{G}_{3}$ (e.g. $14 \cdot 6$ and $24 \cdot 5 \%$, respectively in $P$. Federal in $S_{2}$ ).

Heat treatment decreased carpel weight $(P<0 \cdot 001)$ in both cultivars and in all grain positions (Fig. 3, where carpel weight in the heat-treated spikes was measured at anthesis). This reduction was greater in P. Federal $(28 \%)$ than in B. Ombú $(20 \%)$, and $C_{3}$ showed a greater decrease $(c .35$ and $31 \%$ in $\mathrm{P}$. Federal and B. Ombú, respectively) than proximal carpels (c. 24 and $13 \%$ in P. Federal and B. Ombú). In addition, carpel weight at anthesis depended strongly upon its growth between heading and anthesis (Fig. 3). Similar results were found in $S_{1}$ for both cultivars and all grain positions when the weight of carpels just (4 days) after anthesis was related to the rate of carpel growth from booting to then $(r=$ $0.97 ; P<0.001)$.

Final grain weight of both control and heated spikes showed a quadratic association with carpel weight at anthesis in $\mathrm{S}_{2}$ (Fig. 4). Finally, the environmental conditions (temperature) during the period between heading and anthesis were of critical importance in determining final grain weight, especially for grain positions of relatively low potential (e.g. $G_{3}$ ) which were the most affected in both sowing dates (Fig. 5). It is possible that the greater reduction found in $\mathrm{S}_{2}$ could be related to the fact that the relative increase of temperature was higher in $\mathrm{S}_{2}$ than in $S_{1}$ (36 and $17 \%$, respectively). 

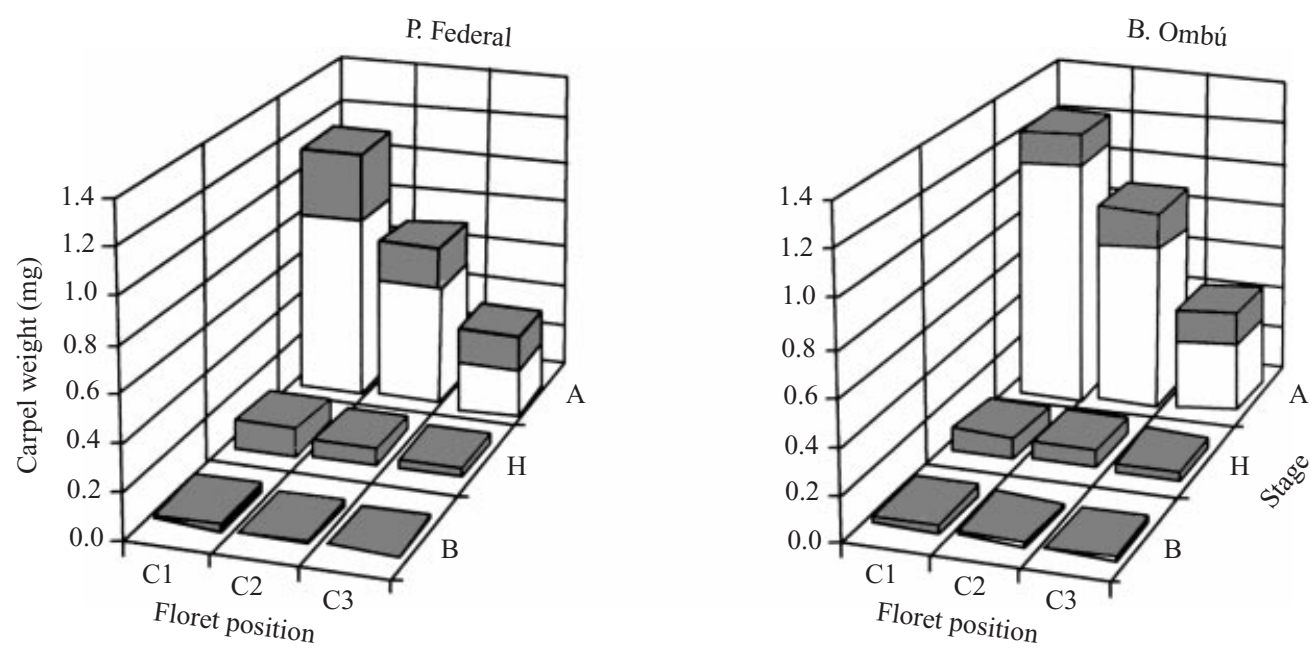

Fig. 3. Carpel weight corresponding to the three most proximal florets (i.e. $\mathrm{C}_{1}, \mathrm{C}_{2}$ and $\mathrm{C}_{3}$ ) at booting (B), heading $(\mathrm{H})$ and anthesis (A) for the cultivars P. Federal and B. Ombú in the second sowing date. At anthesis the open columns represent the weight of carpels grown within the transparent boxes of the heat treatment and the open plus filled columns represent the weight of the corresponding control treatment.

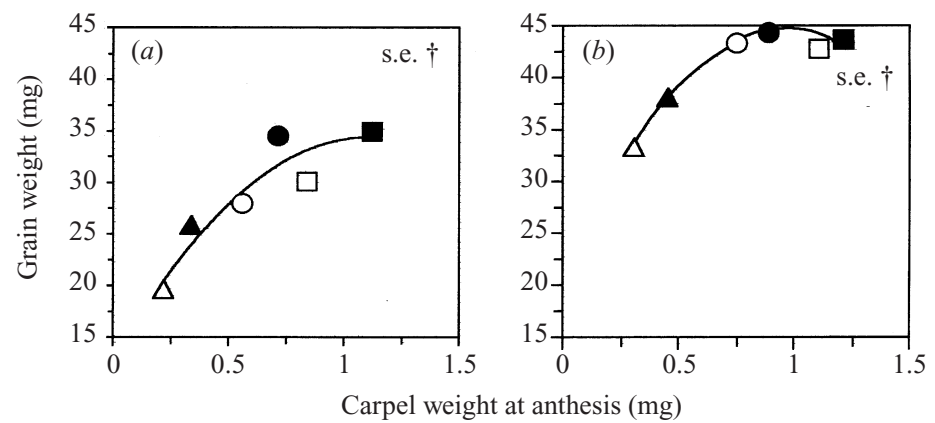

Fig. 4. Association between final grain weight and carpel weight at anthesis in Pro INTA Federal (a) and Buck Ombú (b) in the second sowing date for controls (closed symbols) and the heat treatment (open symbols). The symbols represent different grain positions: $\mathrm{G}_{1}$ (squares), $\mathrm{G}_{2}$ (circles) and $\mathrm{G}_{3}$ (triangles). Lines were fitted by regression $(y=$ $12 \cdot 6+39 \cdot 4 x-17 \cdot 9 x^{2} ; r=0.93, P<0.5$ and $y=20 \cdot 8+49 \cdot 1 x+25 \cdot 3 x^{2} ; r=0.98, P<0.01$ in Pro INTA Federal and Buck Ombú, respectively).

\section{DISCUSSION}

The effect of sowing date (Stapper \& Fischer 1990), genotype (Gleadow et al. 1982; Slafer \& Andrade 1989; Wardlaw et al. 1989; Calderini et al. 1995) and grain position (Slafer \& Savin 1994; Miralles \& Slafer 1995; Kruk et al. 1997) on grain weight potential has been widely recognized. Other studies have shown negative relationships between final grain weight and temperature during grain-filling. For example Wardlaw (1994) showed this negative relationship over the temperature range of $14-27^{\circ} \mathrm{C}$. In addition, most of the studies have explained the differences in potential grain weight by differences in the rate of grain-filling (Sofield et al. 1977; Wardlaw \& Moncur 1995). However, the importance of environmental conditions during a short period (c. 6 days) before anthesis on potential grain weight has not generally been recognized, although the effects of high temperature on kernel damage, especially the occurrence of sterile grains, are known (Tashiro \& Wardlaw 1990). The present study was focused on the influence of temperature in the late stages of the spike development period. The increase in spike temperature was obtained by the use of acrylic boxes which markedly increased maximum temperatures though has almost no effect on minimum temperatures. The effect of a few hours of high temperature can not be assumed to be the same as a continuous temperature even though the daily mean may be the same. However, under crop conditions it is commonly observed that critical increases of temperatures do not 


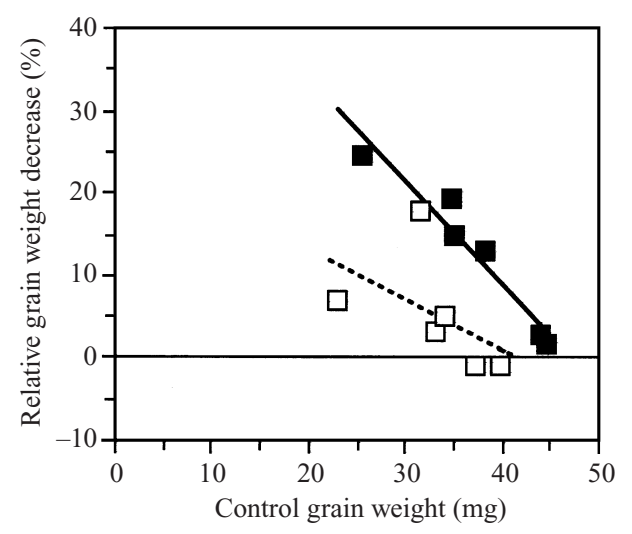

Fig. 5. Relationship between relative grain weight reduction due to the heat treatment (relative to the control treatment) and grain weight of the control treatment for each grain position in the first (open squares) and the second (closed squared) sowing dates. The lines include both cultivars and show the linear regression fitness for the first (dashed lines; $r=0.51, P>0 \cdot 10$ ) and the second (solid lines; $r=0 \cdot 97, P<0 \cdot 01)$ sowings.

occur very rapidly during the day (see Stone \& Nicolas 1995). On the other hand, the use of boxes probably modified the humidity around the heated spikes, especially because the effect of boxes on temperature is variable according to sunshine (i.e. lower humidity in the boxes in higher sunshine). In addition, although the boxes had open bases to allow air circulation around the spikes, it is possible that vapour pressure has been affected by the use of the boxes. Therefore, a possible effect of vapour pressure deficit on final grain weight (independently from the effect of higher temperature per se) should not be discarded in the present work.

The importance of pre-anthesis temperature (more exactly during the period between spike emergence and anthesis) on final grain weight has been shown in the present study, and this result is consistent with the results reported by Wardlaw (1994) for a much more extended period during pre-anthesis under controlled conditions.

A linear relationship between grain weight and the carpel weight at anthesis was reported in barley (Scott et al. 1983), which also appears to hold for grains/ ovules at different positions within the spikelet in Lolium perenne (Warringa et al. 1998). But in wheat, little is known about the influence of floret size on grain weight potential except for the association between grain weight and the weight of spike tissues (including awns) at anthesis found by Fischer \& HilleRisLambers (1978). The study of the relationship between final grain weight and floret parameters in pre-anthesis is relevant to understand the determination of grain weight potential for particular growing conditions. Miralles et al. (1998) have explained differences in final grain weight of proximal grains in isogenic lines for semi-dwarfism of wheat in terms of the number of pericarp cells, which are developed before anthesis. In the present study, an association between final grain weight and carpel weight at anthesis, both for control and heated spikes, was also found. However, this relationship was quadratic, rather than linear. Probably this relationship could be involved with the mechanisms that determine grain weight potential but as the relationship is strongly influenced by $\mathrm{C}_{3}$ and $\mathrm{G}_{3}$ it is not possible to conclude that the effects of different temperature regimes (from ear emergence to anthesis) and grain positions on final grain weight are both consequences of variation in carpel weight. With this in mind, the existence of a carpel weight threshold of c. $1 \mathrm{mg}$ at anthesis for achieving maximum grain weight is suggested, at least for these two cultivars. Finally, it may be hypothesized that cultivars with grains of relatively low potential weight may be less stable in final grain weight than those with genetically heavy grains. For example, differences in final grain weight between proximal and distal grains were better explained by carpel weight than differences between grains 1 and 2 . This may be deduced from the fact that the grains from the distal florets were more responsive than proximal grains, and because for any particular grain position the cultivar with smaller grains (P. Federal) was more responsive than B. Ombú (see Fig. 5 and Table 2). This does not mean that post-anthesis conditions, particularly temperature during grain-filling, are not important in determining final grain weight, but that genetic and environmental factors that modify carpel growth and in turn the weight the carpel may reach set an upper limit to final grain weight.

We thank A. J. Hall (University of Buenos Aires, Argentina) and I. F. Wardlaw (CSIRO, Australia) for critically reviewing an early version of the manuscript. This work was supported by grants from the Universidad de Buenos Aires (AG-107) and Fundacion Antorchas.

\section{REFERENCES}

Bremner, P. M. \& Rawson, H. M. (1978). The weights of individual grains of the wheat ear in relation to their growth potential, the supply of assimilate and interaction between grains. Australian Journal of Plant Physiology 5, $61-72$.
Calderini, D. F., Dreccer, M. F. \& Slafer, G. A. (1995). Genetic improvement in wheat yield and associated traits. A re-examination of previous results and the latest trends. Plant Breeding 114, 108-112.

FisCHER, R. A. (1985). Number of kernels in wheat crops 
and the influence of solar radiation and temperature. Journal of Agricultural Science, Cambridge 105, 447-461.

Fischer, R. A. \& HilleRisLambers, D. (1978). Effect of environment and cultivar on source limitation to grain weight in spring wheats. Australian Journal of Agricultural Research 29, 443-458.

Gleadow, R. M., Dalling, M. J. \& Halloran, G. M. (1982). Variation in endosperm characteristics and nitrogen content in six wheat lines. Australian Journal of Plant Physiology 9, 539-551.

JANDELL. (1991). Table Curve V. 3·0. User's Manual Version 3.0 AISN Software. Corte Madera, California: Jandel Scientific.

Kruk, B. C., Calderini, D. F. \& Slafer, G. A. (1997). Grain weight in wheat cultivars released from 1920 to 1990 as affected by post-anthesis defoliation. Journal of Agricultural Science, Cambridge 128, 273-281.

Loss, S. P., Kirby, E. J. M., Siddique, K. H. M. \& Perry, M. W. (1989). Grain growth and development of old and modern Australian wheats. Field Crops Research 21, 131-146.

Magrin, G. O., Hall, A. J., Baldy, C. \& Grondona, M. O. (1993). Spatial and interannual variations in the photothermal quotient: implications for the potential kernel number of wheat crops in Argentina. Agricultural and Forest Meteorology 67, 29-41.

Miralles, D. J. \& Slafer, G. A. (1995). Individual grain weight responses to genetic reduction in culm length in wheat as affected by source-sink manipulations. Field Crops Research 43, 55-66.

Miralles, D. J., Dominguez, C. F. \& Slafer, G. A. (1996). Grain growth and postanthesis leaf area duration in dwarf, semidwarf and tall isogenic lines of wheat. Journal of Agronomy and Crop Science 177, 115-122.

Miralles, D. J., Calderini, D. F., Pomar, K. P. \& D'Ambrogio, A. (1998). Dwarfing genes and cell dimensions in different organs of wheat. Journal of Experimental Botany 49, 1119-1127.

Pedrol, H. M. \& Castellarín, J. M. (1989). Respuesta al ambiente y estabilidad relativa de cultivares de trigo pan en la subregion triguera II norte. In Informe Técnico 39. INTA Oliveros, Pcia. de Santa Fé, República Argentina.

Rijven, A. H. G. C. \& Banbury, C. A. (1960). Role of the grain coat in wheat grain development. Nature 188, 546-547.

Savin, R. \& Nicolas, M. E. (1996). Effects of short periods of drought and high temperature on grain growth and starch accumulation of two malting barley cultivars. Australian Journal of Plant Physiology 23, 201-210.

Scott, R. W., Appleyard, M., Fellowes, G. \& Kirby, E. J. M. (1983). Effect of genotype and position in the ear on carpel and grain growth and mature grain weight of spring barley. Journal of Agricultural Science, Cambridge 100, 383-391.

Simmons, S. R., Crookston, R. K. \& Kurle, J. E. (1982). Growth of spring wheat kernels as influenced by reduced kernel number per spike and defoliation. Crop Science 22, 983-988.

Slafer, G. A. \& Andrade, F. H. (1989). Genetic improvement in bread wheat (Triticum aestivum, L.) yield in Argentina. Field Crops Research 21, 289-296.

Slafer, G. A. \& Miralles, D. J. (1992). Green area duration during the grain filling period of an Argentine wheat cultivar as influenced by sowing date, temperature and sink strength. Journal of Agronomy and Crop Science 168, 191-200.

Slafer, G. A. \& Savin, R. (1994). Grain mass change in a semi-dwarf and a standard-height wheat cultivar under different sink-source relationships. Field Crops Research 37, 39-49.

Slafer, G. A., Satorre, E. H. \& Andrade, F. H. (1994). Increases in grain yield in bread wheat from breeding and associated physiological changes. In Genetic Improvement of Field Crops (Ed. G. A. Slafer), pp. 1-68. New York: Marcel Dekker Inc.

Sofield, I., Evans, L. T., CoOK, M. G. \& Wardlaw, I. F. (1977). Factors influencing the rate and duration of grain filling in wheat. Australian Journal of Plant Physiology 4, 785-797.

STAPPER, M. \& FisCher, R. A. (1990). Genotype, sowing date and planting spacing influence on high-yielding irrigated wheat in southern New South Wales. I. Phasic development, canopy growth and spike production. Australian Journal of Agricultural Research 41, 997-1019.

Stone, P. J. \& Nicolas, M. E. (1995). Comparison of sudden heat stress with gradual exposure to high temperature during grain filling in two wheat varieties differing in heat tolerance. I. Grain Growth. Australian Journal of Plant Physiology 22, 935-944.

TASHIRO, T. \& WardLaW, I. F. (1990). The response to high temperature shock and humidity changes prior to and during the early stages of grain development in wheat. Australian Journal of Plant Physiology 17, 551-561.

WardLAW, I. F. (1994). The effect of high temperature on kernel development in wheat: variability related to preheading and post-anthesis conditions. Australian Journal of Plant Physiology 21, 731-739.

WARDLAW, I. F. \& Moncur, L. (1995). The response of wheat to high temperature following anthesis. I. The rate and duration of kernel filling. Australian Journal of Plant Physiology 22, 391-397.

Wardlaw, I. F., Dawson, I. A., Munibi, P. \& Fewster, R. (1989). The tolerance of wheat to high temperatures during reproductive growth. I. Survey procedures and general response patterns. Australian Journal of Agricultural Research 40, 1-13.

Warringa, J. W., Struik, P. C., De Visser, R. \& Kreuzer, A. D. H. (1998). The pattern of flowering, seed set, seed growth and ripening along the ear of Lolium perenne. Australian Journal of Plant Physiology 25, 213-223.

Zadoks, J. C., Chang, T. T. \& KonzaK, C. F. (1974). A decimal code for the growth stages of cereals. Weed Research 14, 415-421. 